\title{
ANÁLISE MORFOTECTÔNICA DA BACIA HIDROGRÁFICA DO RIO IVAİ-PR, CURSO INFERIOR
}

\section{MORPHOTECTONIC ANALYSIS OF IVAI RIVER BASIN, LOWER COURSE}

\begin{abstract}
Manoel David Souza Junior
Universidade Estadual Paulista Júlio de Mesquita Filho - Instituto de Geociências e Ciências Exatas - CEP 13506-900 - Rio Claro, SP - Brasil

E-mail:manoeldavid@universitube.com.br

Manoel Luiz dos Santos

Universidade Estadual de Maringá - Centro de Ciências Humanas Letras e Artes, Departamento de Geografia CEP 87020-900-Maringa, PR - Brasil E-mail:mldsantos@uem.br

Eduardo Salamuni

Universidade Federal do Paraná. Departamento de Geologia - CEP 81530-900 - Curitiba, PR - Brasil E-mail: salamuni@ufpr.br

José Cândido Stevaux

Universidade Estadual de Maringá - Centro de Ciências Humanas Letras e Artes, Departamento de GeografiaCEP 87020-900-Maringa, PR - Brasil

E-mail: jcstevaux@uem.br

Norberto Morales

Universidade Estadual Paulista Júlio de Mesquita Filho - Instituto de Geociências e Ciências Exatas - CEP 13506-900 - Rio Claro, SP-Brasil E-mail:nmorales@rc.unesp.br
\end{abstract}

Informações sobre o Artigo

Data de Recebimento:

$11 / 12 / 2012$

Data de Aprovação: 09/06/2013

\section{Palavras-chave:}

Neotectônica; rio Ivaí; geomorfogia fluvial.

\section{Keywords:}

Neotectonics; Ivaí river; fluvial geomorphology.

\begin{abstract}
Resumo
Feições geomorfológicas encontradas nas sub-bacias associadas ao curso inferior do rio Ivaí indicam movimentações neotectônicas neste local. A principal indicação se refere a três leques aluviais alinhados na direção NE-SW que refletem uma falha normal sobre a planície do rio Ivaí próximo a sua foz, junto ao rio Paraná. No entanto, análises sobre os padrões de drenagem, fator de assimetria das sub-bacias e lineamentos estruturais, através de métodos de sensoramento remoto, ferramentas geoestatísticas e trabalho de campo, denotam certa complexidade estrutural não explicada somente por soerguimento e abatimento de blocos. Outras feições como estreita planície de inundação com meandros encaixados em fraturas NE-NW, tributários alinhados N-S e fraturas subverticais, corroboram para a dedução de cisalhamento simples atuando ao longo do curso do rio Ivaí. Portanto, este estudo tem a finalidade de interpretar o desenvolvimento dessas feições geomorfológicas fluviais e compará-las a modelos clássicos já consagrados pela geologia estrutural.
\end{abstract}




\begin{abstract}
Geomorphological features found in the sub-basins associated with the lower reaches of the Ivai River indicate neotectonic movements. The main geomorphological feature refers to the three alluvial fans lined up in the NE-SW direction that reflect a normal fault on the flood plain of the Ivai river near its mouth along the Parana River. However, analyzes on the drainage patterns, asymmetry factor of sub-basins and structural lineaments, using methods of remote sensing, geostatistical tools and field work, show some structural complexity that can not be explained only by uplift and subsidence of blocks. Other features such as narrow floodplain with meanders embedded in fractures NE-NW, tributaries aligned NS and subvertical fractures, corroborate the deduction of simple shear acting along the river course Ivaí. Therefore, this study aims to interpret the development of these fluvial geomorphological features and compare them to classical models already established by the structural geology.
\end{abstract}

\section{Introdução}

A área estudada está localizada entre o curso inferior do rio Ivaí e os topos de colinas que separam sua bacia hidrográfica das demais e abrange cerca de $14.000 \mathrm{~km}^{2}$ no trecho que segue do município de Tapira ao município de Icaraima, onde encontra sua foz com rio Paraná (Figura 1).

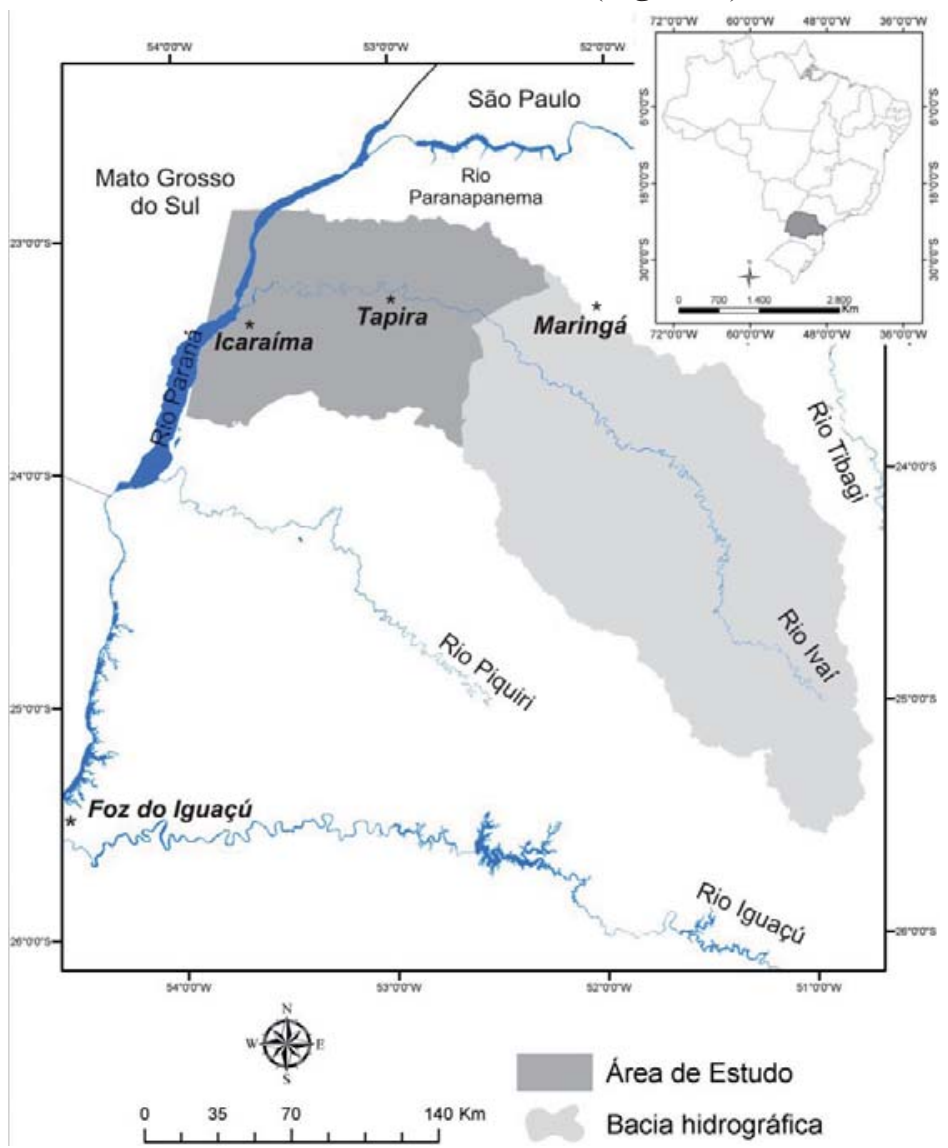

Figura 1 - Localização da área estudada.

O rio Ivaí é um importante afluente do rio Paraná. Em seu curso inferior sua dinâmica hidrológica é influenciada pelo rio Paraná, principal drenagem da Bacia Sedimentar do Paraná. O rio Ivaí que, em seus $685 \mathrm{~km}$ de extensão, corta à montante as formações geológicas do Grupo Passa Dois (Neopermiano), em seu trecho médio basaltos da Formação Serra Geral (Cretáceo) e à jusante, em seu curso inferior, sedimentos quaternários e a Formação Caiuá (Neo-cretáceo) (SANTOS et al, 2008) (Figura 2). Sua bacia hidrográfica ocupa uma área de $36.587 \mathrm{~km}^{2}$ (FUGITA, 2009). O trecho de baixa declividade deste rio, próximo sua foz no rio Paraná, apresenta gradiente hidráulico de cerca de $0,5 \mathrm{~m} / \mathrm{km}$. Sua planície aluvial tem aproximadamente $150 \mathrm{~km}$ de comprimento e largura variando de $600 \mathrm{~m}$ até $13 \mathrm{~km}$, nesse local o rio Ivaí apresenta padrão meandrante e encaixado (SANTOS, op cit).

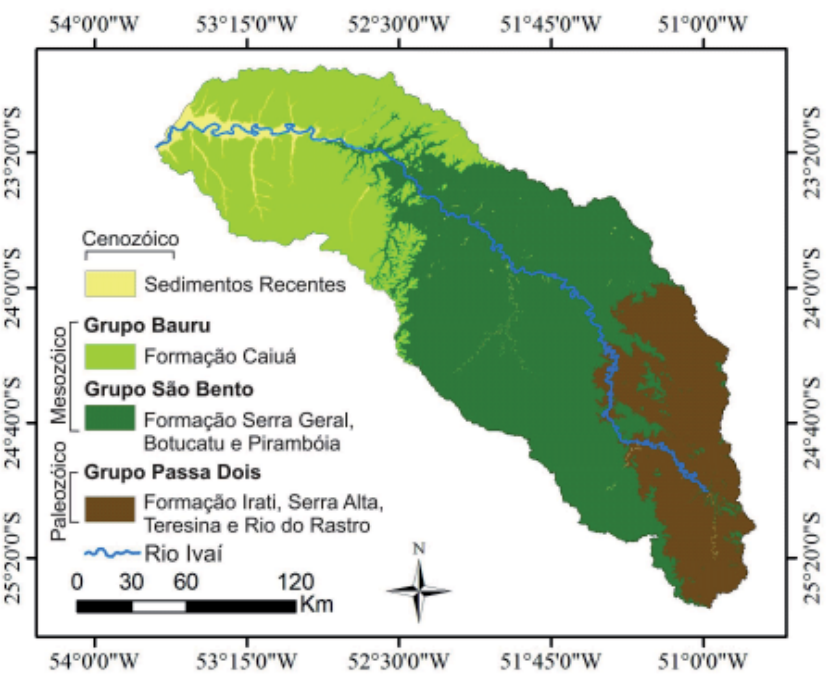

Figura 2 - Área da Bacia Hidrográfica do rio Ivaí, com cerca de $36.587 \mathrm{~km}^{2}$ e as unidades geológicas aflorantes na região, a coloração mais clara no mapa, corresponde à planície de inundação (Alves 2012).

Santos et al. (2008) subdividiram a planície aluvial do rio Ivaí em seis unidades morfoestratigráficas: Planície Paraná-Ivaí, Planície Ivaí, Terraço Paraná, Terraço Ivaí, Leque Aluvial e Canal Fluvial. A conformação destas unidades 
é resultado de processos endógenos e exógenos atuantes na formação da paisagem.

O objetivo deste artigo é analisar os processos tectônicos ligados à formação do leque aluvial do Córrego Dourado, localizado na planície aluvional do rio Ivaí, junto a sua foz no rio Paraná e contextualizá-lo a outros estudos realizados nesta região.

Processos hidro-dinâmicos de escala regional vêm sendo estudados sistematicamente no rio Ivaí desde a década de 1970: Bittencourt (1982) quantificou o grande volume de sólidos carreados pelo rio; Santos (1999) estimou a perda de solo da bacia; Andrade (2002) descreveu o clima da região; Ramos (1973) e Destefani (2005) discorreram sobre o regime de débito dos sedimentos neste rio; Barros (2006), Biazin (2005) e Kuerten (2006) estudaram a hidrodinâmica do canal; Santos et al. (2008) descreveram processos epirogenéticos; Couto (2010) e Manieri (2010) estudaram a morfotectônica das áreas a montante da bacia do rio Ivaí, sendo a área de sua foz ainda pouco pesquisada quanto a este fator.

Segundo Santos et al.(2008), a Planície Paraná-Ivaí ocupa uma área de $48 \mathrm{~km}^{2}$ e possui baixo gradiente variando entre $12 \mathrm{a} 3 \mathrm{~cm} / \mathrm{km}$. A morfogênese local é atribuída à ação dos rios Ivaí e Paraná, sob intervenções neotectônicas. Neste local ocorrem depósitos fluviais de idade quaternária. Com relação à construção dos terraços, Fortes et al. (2005) consideram que grande parte do compartimento local teria expressiva influência da tectônica recente, e a calha do rio Paraná estaria encaixada em modelo de falhas antitéticas.

No rio Ivinhema, Fortes et al. (2005) associam a ocorrência de leques e conglomerados a processos neotectônicos em conjunto com mudanças climáticas ocorridas no Holoceno. Segundo esses autores, em sua área de estudo os leques bordejam níveis de terraços que apresentam cobertura pedológica da Formação Caiuá.

\section{Métodos}

A base deste trabalho foi a utilização de imagens SRTM (Shuttle Radar Topography Mission) obtidas na banda C e resolução de $90 \mathrm{~m}$ por radar interferométrico InSAR durante missão conjunta da National Aeronautics and Space Administration (NASA) e National Imagery and Mapping Agency (NIMA) em fevereiro de 2000. Os acessos a estas informações ocorreram entre os meses de agosto e dezembro de 2010 , através dos sites http://edc.usgs.gov/srtm/data/obtainingdata.html e http://e0srp01u.ecs.nasa.gov/. Estas imagens são identificadas como:SF-22-Y-A, SF-22-Y-B e SF-22-Y-C) e os dados utilizados neste trabalho foram processadas com o auxílio dos softwares Global Mapper e Spring.

Para a aferição dos dados obtidos através do sensoramento remoto, foram realizadas três etapas de trabalho de campo, totalizando a visitação de 65 pontos de observação.
A primeira etapa teve caráter de reconhecimento geral da área, onde foram observadas as feições do relevo na foz do rio Ivaí junto ao rio Paraná, as feições de relevo e vegetação desenvolvidas sobre o leque aluvial do córrego Dourado, amostragem e reconhecimento dos sedimentos da planície de inundação do rio Ivaí; e a tentativa de localização em campo, de sísmitos identificados em foto aérea de 1970, essas estruturas não puderam ser reconhecidas em campo devido a mecanização do solo para o uso agrícola.

A segunda etapa de campo, que consistiu na navegação do curso inferior do rio Ivaí em seus $120 \mathrm{~km}$, entre a Corredeira do Ferro (basaltos da Formação Serra Geral) e a porção sudoeste da planícies e foz do rio Ivaí (arenitos da Formação Caiuá do Grupo Bauru). Esta etapa consistiu no mapeamento litológico, medições estruturais de planos de falhas, fraturas e acamamentos deposicionais, e tentativa de localização de superfícies ferruginosas e lateríticas. A última etapa de trabalho de campo foi realizada com o intuito de observar os limites da bacia hidrográgica do rio Ivaí, processos de erosão de encostas, ravinas e outras feições de topo de colinas, assim como medidas estruturais de fraturas e falhas. Devido a dificuldade de acesso aos topos de colinas da margem esquerda da bacia do curso inferior do rio Ivaí, poucos pontos foram visitados neste setor. No entanto, estes locais são bastante homogêneos quanto a sua litologia e relevo, não comprometendo assim o resultado do trabalho.

Através do uso do software Openstereo 01.2 foram plotadas as medidas de direção e mergulho das fraturas em estereograma de igual área (Schmidt-Lambert), permitindo a plotagem dos planos de fraturas e seus pólos, isolinhas de concentração e a obtenção da direção preferencial das fraturas.

A classificação da rede de drenagem seguiu o modelo de Strahler (1952) adaptado por Soares e Fiori (1976).

Para classificação dos leques aluviais foi utilizado a referência de Suguio (2003) sobre os trabalhos de Stanistreet e McCarthy (1993). Segundo estes autores, os leques podem ser subaquáticos (geralmente em sistemas fluviais entrelaçados) e subaéreos. Quando depositados em ambientes marinhos, formam os leques deltáicos. Seu ângulo de declive e extensão dependem de sua composição. Leques de argilitos e folhelhos apresentam alta declividade e o dobro da largura do que leques de composição arenosa. Sua extensão também depende da litologia da área fonte, clima, história tectônica e espaço de acomodação. Esta classificação destinguiu basicamente três tipos de leques aluviais:

- Leques dominados por processos gravitacionais. Apresentam forte controle climático e ou tectônico ativo. Desenvolvem em ambientes subaquáticos, depósitos de fácies de corrente de turbidez. Em ambientes subaéreos desenvolvem fácies de fluxo de detritos e corridas de lama; 
- Leques de rios entrelaçados, desenvolvidos em climas úmidos (por exemplo: leque de Kosi na Índia);

- Leques de rios meandrantes de baixa sinuosidade, desenvolvidos em climas úmidos (por exemplo: Rio Okavango em Botswana).

\section{Resultados e discussão}

As unidades morfoestratigráficas da planície do rio Ivaí apresentam cotas topográficas que se igualam inúmeras vezes. Esta coincidência de ambientes deposicionais distintos em uma área relativamente pequena dá indícios de que fatores neotectônicos podem ser causadores desta condição.

As drenagens associadas às sub-bacias do rio Ivaí apresentam ordens variando entre primeira e até oitava, segundo a classificação de Strahler (1952). Segundo a classificação de Soares e Fiori (1976) podem ser assim caracterizadas:

- Grau de integração: em sua maior parte é médio;

- Grau de continuidade: médio em sua maior parte;

- Densidade: de maneira geral a área apresenta uma densidade de drenagem da ordem de $4,7 \mathrm{~km} / \mathrm{km}^{2}$, ou seja, alta densidade;

- Tropia: multidirecional ordenada em sua maior parte e com pontos multidirecionais desordenados na porção noroeste e sudeste;

- Grau de controle: forte nos tributários principais do rio Ivaí;

- Sinuosidade: mista;

- Angularidade: média nas drenagens de primeira e segunda ordem e alta nas drenagens principais que ligam aos tributários;

- Ângulo de junção: agudo entre as drenagens de primeira e segunda ordem e retos nas drenagens principais que ligam aos tributários.

Pela classificação mais simplificada de Teixeira et al. (2000), os padrões de drenagem das sub-bacias são de forma geral dendrítico

Sobre os solos e a organização da bacia, destaca-se a maior ocorrência de argissolos na área central das sub-bacias da margem esquerda do rio Ivaí (Figura 3). Isto pode estar relacionado ao soerguimento desta região, o que pode ser resultado de um possível falhamento no centro deste bloco. A topografia da área faz com que esta localmente sofra menor processo de lixiviação pluvial e o solo apresente perfil de alteração mais desenvolvido com a estagnação dos argilominerais. Outra hipótese seria que, com o soerguimento do bloco da margem esquerda, um maior nível de erosão dos fundos de vales à montante das cabeçeiras, poderia favorecer o acúmulo de argilominerais nestas porções mais baixas topograficamente.

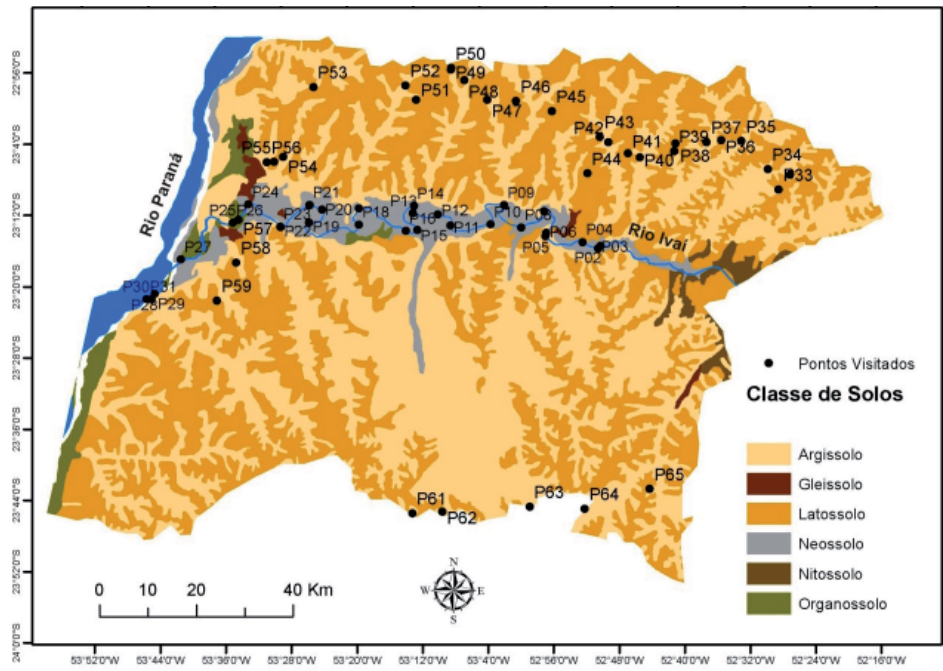

Figura 3-Localização dos pontos visitados em trabalhos de campo, indicados sobre o mapa pedológico da área estudada. O Mapa de solos foi elaborado a partir da base cartográfica obtida pelo levantamento de reconhecimento dos solos do estado do Paraná (EMBRAPA, 1984).

Os pontos visitados em campo de maneira geral encontram-se em latossolos. As vertentes de ambas as bordas da bacia ocorrem em forma de colinas amplas e suaves, chegando quase à formação de planaltos. As colinas da margem esquerda apresentam-se com maior declividade.

A Figura 4 apresenta a localização dos pontos onde foi possível reconhecer um padrão sistemático de fraturas em campo, bem como de se obter medidas de suas orientações. Somente em um ponto (Ponto 23) foi observado rejeito de falha de $2 \mathrm{~cm}$ indicando uma falha normal, a partir desta observação as fraturas encontradas neste mesma orientação foram consideradas falhas normais. Não há material que percole ou se cristalize nos planos de fratura.

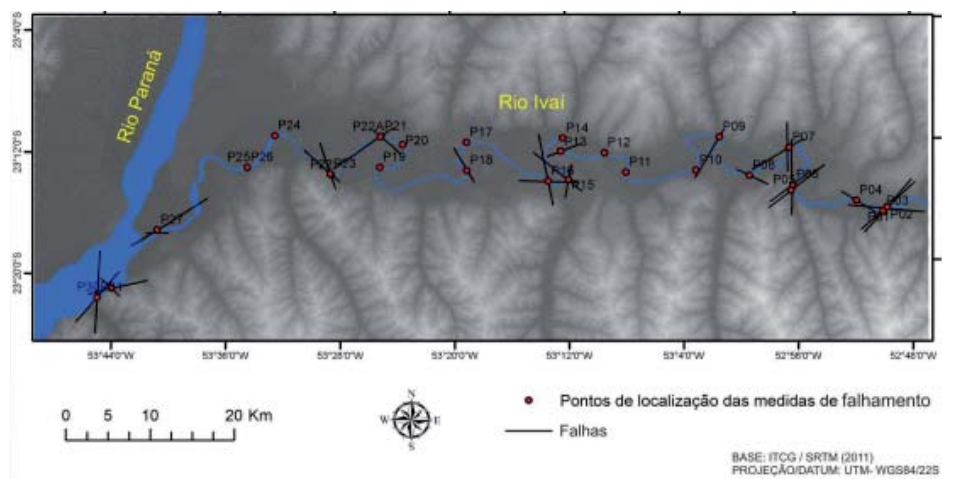

Figura 4-Localização dos pontos de coleta de medidas estruturais em campo. 
A Figura 5 apresenta a plotagem das medidas de fraturas, falhas e planos de acamamento no esterograma de Schmidt-Lambert. As linhas cinzas representam os planos de fraturas, a linha vermelha o acamamento deposicional sendo a estrela azul o pólo deste plano, os pontos negros representam os pólos dos planos de fraturas e as isolinhas avermelhadas a densidade dos pólos dos planos de fraturas.

Foram separadas as famílias de fraturas encontradas nos parcos afloramentos da região. É possivel distinguir três agrupamentos denominados F, F1 e F2.

As medidas da família $F$ estariam relacionadas a juntas secundárias e de menor intensidade com direção preferencial de N-S. Desta família foram coletadas apenas 7 medidas ao longo dos $120 \mathrm{~km}$ percorridos no rio Ivaí.

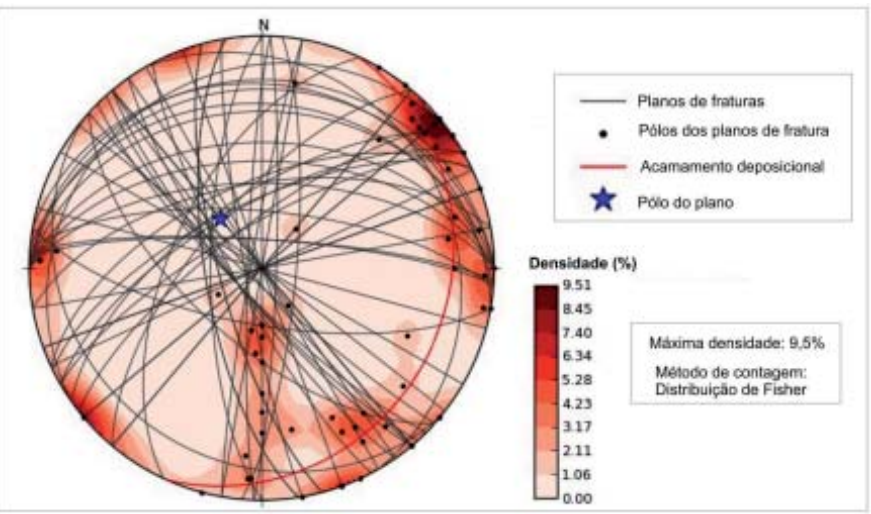

Figura 5 - Estereograma com as medidas estruturais das fraturas ao longo do rio Ivai em seu curso inferior.

As medidas da família $\mathrm{F} 1$ possuem direção preferencial NW-SE, apresentam alto inclinação de mergulho, variando entre $80^{\circ}$ a $90^{\circ}$ e são concentradas na mesma direção, ou seja, tem um trend melhor definido em torno de N40W. Foram coletadas 18 medidas deste grupo. Esta pode ser considerada a direção preferencial das fraturas nas margens do rio Ivaí e estaria diretamente relacionada com o encaixe dos meandros nesta direção.

As medidas da família F2 foram as mais facilmente identificadas em campo e seu trend tem direção preferencial NE-SW que varia entre N40E a N80E, ou seja com variação maior da dispersão dessas fraturas. Apresentam menores ângulos de mergulho variando entre $60^{\circ}$ a $80^{\circ}$ graus para SE. Foram coletadas 27 medidas deste grupo.

O ponto 01 (leste da área) marca o limite entre os arenitos da Formação Caiuá e os basaltos e diabásios da Formação Serra Geral, localmente conhecido como Corredeira do Ferro. Neste ponto foi mapeado um dique de diabásio com aproximadamente $50 \mathrm{~m}$ de extensão, cortado transversalmente pelo rio Ivaí. Devido ao intenso fraturamento deste dique, foi difícil distinguir um trend principal das fraturas pois a rocha, além dos lineamentos estruturais apresentam juntas de dilatação devido ao alívio de carga e resfriamento. No entanto, as direções ao redor de N30W (família F1) foram as mais expressivas, onde se encaixa parte dos meandros do rio Ivaí.

Ressalta-se no trecho estudado a pequena quantidade de afloramentos encontrados ao longo do curso inferior do rio Ivaí. A maioria da área está coberta por sedimentação quaternária. Parte das margens do curso inferior do rio Ivaí segue paralelamente aos planos de fratura encontrados, indicando que, pelo menos parcialmente, os planos de fraturas serviram de controle para a erosão e inserção de vales encaixados.

Dentre as feições morfológicas mais importantes da área estudada, encontram-se os leques aluviais, especialmente na região do Pontal do Tigre (foz do rio Ivaí).

Nas imediações do Pontal do Tigre encontra-se o maior leque aluvial da região estudada (Figura 6). O leque está localizado na margem esquerda do rio Ivaí, entre os pontos P21 e P25. Este leque se formou na foz do córrego Dourado, que apresenta uma pequena bacia de captação. Este córrego drena áreas de arenitos da Formação Caiuá e deposita seus sedimentos sobre a planície do rio Ivaí, após cruzar uma crista de relevo alinhada. Este lineamento separa relevo elevado e relevo rebaixado, indicadores respectivamente de bloco soerguido e bloco abatido, em arranjo morfotectônico de falha normal.

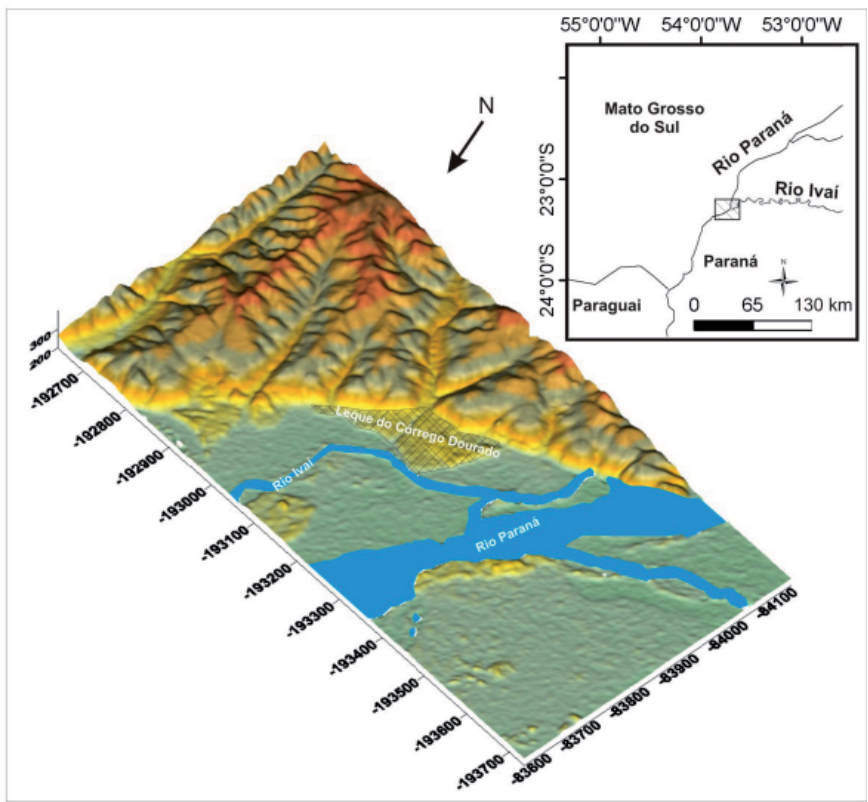

Figura 6-Leque aluvial do córrego Dourado, realçado em modelo digital do terreno.

Morais (2010) obteve uma datação dos sedimentos da planície de inundação sotoposto ao leque aluvional com o método de Luminescência Opticamente Estimulada (LOE) que revelou idade de cerca de 1.600 anos A. P. Segundo 
outros autores (STEVAUX, 1993; JABUR, 1992; SANTOS, 1997), durante o intervalo de 3.500 e 1.500 anos A. P. ocorreram períodos de aridez que levariam a formação de leques aluviais na região.

O leque do córrego Dourado apresenta cerca de $17 \mathrm{~km}^{2}$ e elevação de $15 \mathrm{~m}$ da base da planície até o terraço. Com relação a idade de deposição (1.600 anos A.P.) e sua altura (15 $\mathrm{m})$ pode-se inferir que houve um rebaixamento da planície em relação ao terraço da ordem de $9,37 \mathrm{~mm} /$ ano até o presente.

Segundo a classificação proposta por Stanistreet e McCarthy (1993), o leque do córrego Dourado pode ser considerado como um leque meandrante de baixa sinuosidade, com presença de pequenos meandros abandonados.

A interpretação dos dados de sensoramento remoto e trabalhos de campo levaram a delimitação da região em distintas áreas morfológicas. Há predominância de áreas planas, denotadas como planície aluvial do rio Ivaí ao longo de seu curso inferior e também presença dominante de colinas amplas. A Figura 7 apresenta a subdivisão dos domínios geomorfológicos da área e os perfis topográficos traçados na área estudada (Figura 8) geradas a partir das imagens SRTM. Morfologicamente a planície do rio Ivaí nas imediações de sua foz é retrabalhada pelos sistemas fluviais do rio Ivaí e Paraná. Feições morfológicas como paleocanais e terraços fluviais denotam a evolução deste sistema durante o Holoceno e Pleistoceno (SANTOS et al., 2008).

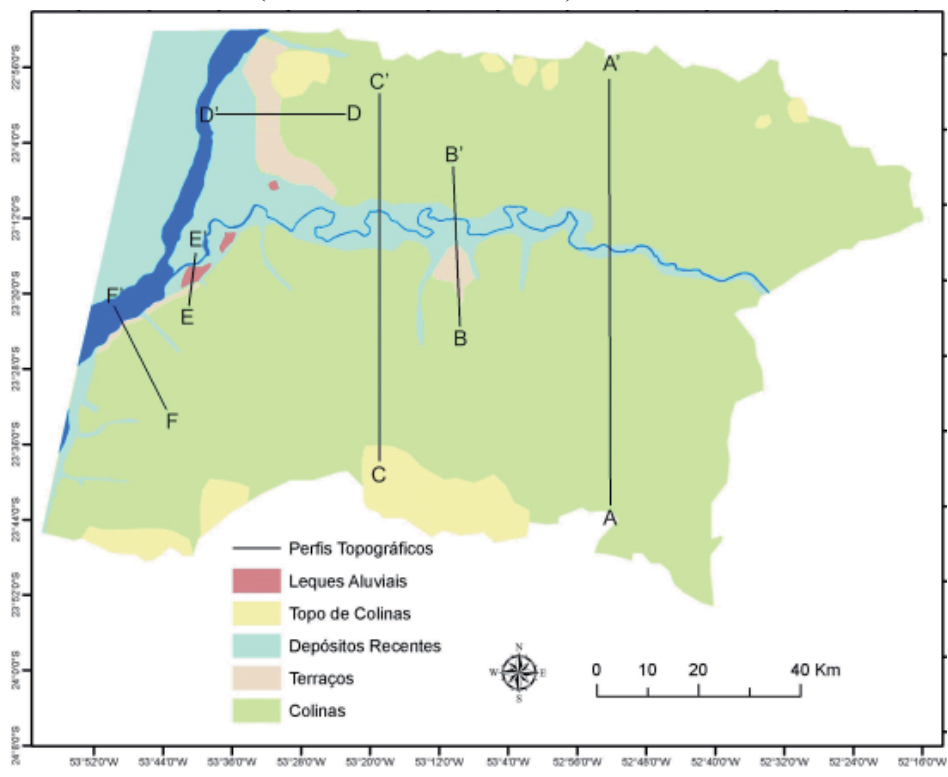

Figura 7 - Mapa geomorfológico da área de estudo.

As zonas homólogas podem ser compartimentadas em áreas de diferentes domínios geomorfológicos. Assim pode-se separar a área em 5 domínios distintos:

Subdomínio dos topos de colinas. Este domínio é evidenciado pela desorientação das drenagens nas porções mais próximas dos limites da bacia hidrográfica do rio Ivaí em seu curso inferior. A forma desorganizada das drenagens nesta região se deve ao baixo gradiente desta área formando quase planaltos nos topos das colinas divisoras das bacias hidrográficas (por exemplo: o limite da bacia do rio Ivaí em seu curso inferior e a bacia do rio Piquiri). Esta região possui baixa declividade, extensas e suaves colinas, sendo de difícil observação in loco qualquer componente estrutural macrosocópio.

- Subdomínio de colinas amplas em meia vertente. Apresentam declividades suaves, no entanto, um pouco mais íngremes que as colinas de topo de vertentes das proximidades dos divisores das bacias hidrográficas, marcado pela orientação das drenagens principais. Estas feições são delimitadas na maioria dos perfis topográficos logo acima da planície. No entanto, nos perfis B-B' e D- D', há presença de terraços em uma das margens cortadas pelo perfil.

- Colinas amplas com solo de alteração da Formação Caiuá e afloramentos da mesma. Abrange grande parte da área e se apresentam de forma paralela às grandes drenagens das sub-bacias do curso inferior do rio Ivaí. Estas colinas estão alinhadas na direção N-S e WNW-ESE, alinhamento preferencial dos principais tributários do rio Ivaí em seu curso inferior. De acordo com as análises de lineamentos estruturais e da rede de drenagem, pode-se dividir este em subdomínios devido à evidência de movimentação de blocos tectônicos distintos nesta porção. Estes subdomínios seriam colinas amplas em "meia vertentes", ou seja, sub-bacias hidrográficas inseridas dentro da bacia do rio Ivaí em seu curso inferior, e colinas de topos divisores de bacias.

- Terraços nas margens superiores do rio Ivaí, compostos por superfícies planas de material arenoso inconsolidado, proveniente do transporte de solos de alteração da Formação Caiuá. Nestes terraços também se encontram níveis centimétricos de seixos em matriz ferruginosa (limonitizados). Esta feição geomorfológica é reconhecida e delimitada nos perfis B-B', D-D', E'-E, F-F' (Figura 8).

- Depósitos fluviais recentes, com planícies estreitas espalhadas ao longo do curso inferior do rio Ivaí e nas proximidades da foz do rio Paraná. Esta área de planície de inundação atualmente se encontra alterada de suas características naturais, pois vem sendo sistematicamente utilizada como área de plantio nos últimos anos. Suas fases de alagamento natural, hoje são controladas por canais e drenos que delimitam sua cheia independente da estação do ano. Todos os perfis topográficos (Figura 8) apresentam elementos na paisagem contendo as planícies, mas especificamente os perfis $\mathrm{E}^{\prime}$-E, F-F' destoam esse domínio geomorfológico.

- Leques Aluviais que aparecem nas proximidades da foz do rio Ivaí com o rio Paraná, depositando-se sobre a planície destes rios. Esta feição está representada no perfil $E^{\prime}$-E (Figura 8). 

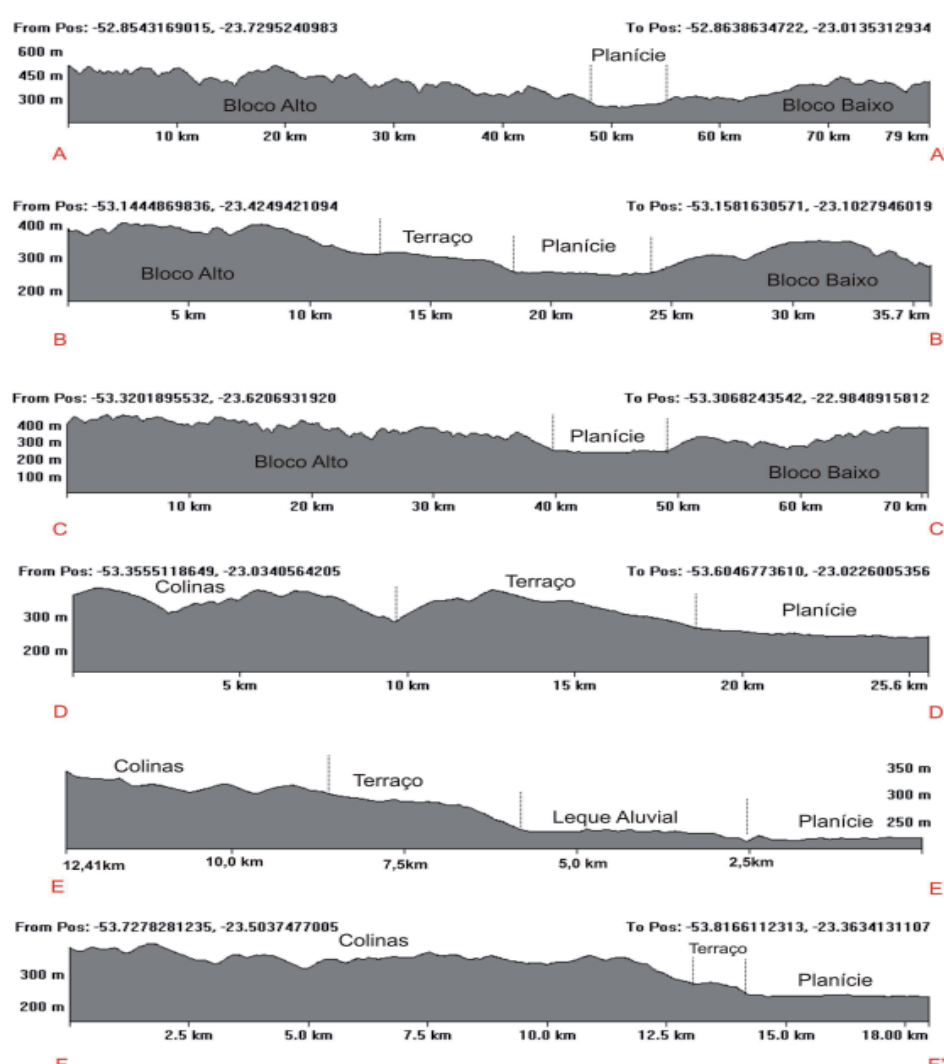

Figura 8-Perfis topográficos da área estudada.

Com base nos dados levantados em campo e o sensoramento remoto, foi possível gerar o mapa morfotectônico (Figura 9) que apresenta de forma interpretativa, a análise dos elementos estruturais, geológicos e morfológicos coletados ou inferidos na área estudada.

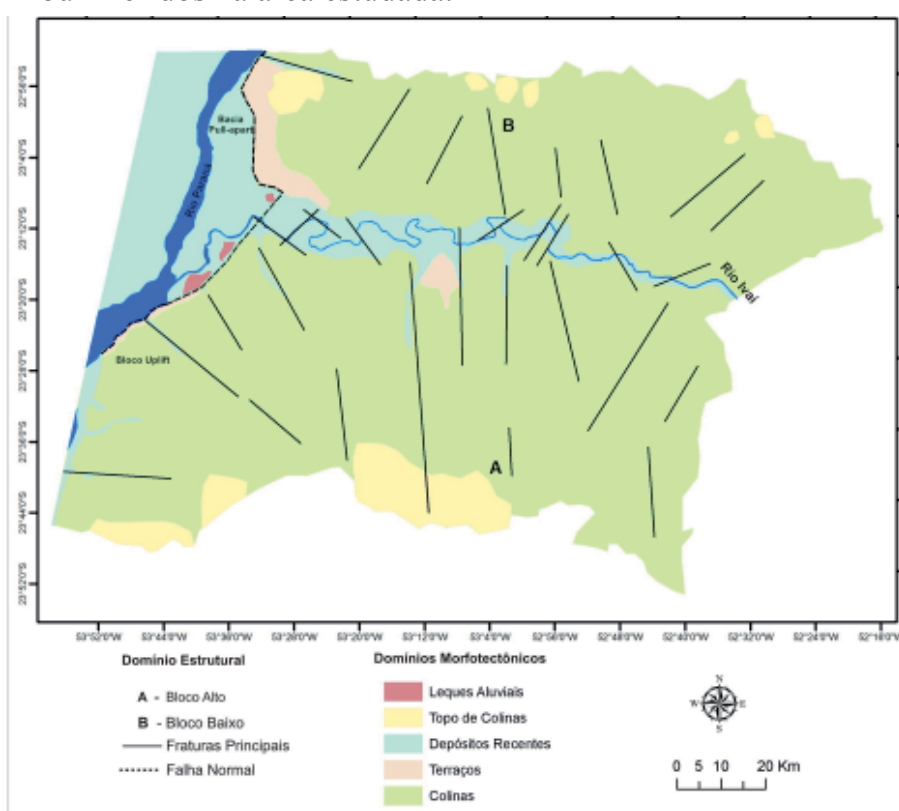

As elevadas cotas hipsométricas nas porções sudeste, nas colinas e topos de vertentes da bacia, principalmente na margem esquerda do rio Ivaí, pode ser influência da melhor preservação das rochas basálticas da Formação Serra Geral e também manifestação do soerguimento do Arco de Ponta Grossa localizado a sudoeste da área.

De acordo com as observações dos perfis e dos padrões de drenagem da área constatou-se que a margem esquerda do rio Ivaí corresponde a um Bloco Alto e a margem direita a um Bloco Baixo.

Feições lineares importantes são as fraturas de direção NW-SE e NE-SW que cruzam as áreas de colinas, terraços e planícies. Neste contexto o rio Ivaí corre em possíveis planos de falhas formando o padrão encaixado.

\section{Conclusão}

Os leques aluviais encontrados na planície do rio Ivaí, em sua foz próximo ao rio Paraná, estão alinhados com direção N52E e indicam falha normal. Esta falha tem caráter recente e segundo os estudos de Franco et al (2008) poderiam ter idade de $40 \mathrm{Ka}$ A.P. Outra hipótese para o surgimento destes leques estaria ligada ao curto período de clima mais seco identificado na área durante o Holoceno Médio (Stevaux, 2000). Nessas condições os processos de formação do leque atuariam sobre uma topografia favorável pré-existente gerada ao final do Pleistoceno.

O rio Ivaí, em seu curso inferior, corre na direção E-W encaixados em um sistema de fraturas com trend NE-NW. Observa-se que os rios tributários das sub-bacias que deságuam no rio Ivaí não sofrem influência dos alinhamentos estruturais que ocorrem na planície do rio Ivaí. Estes rios tributários possuem em sua maioria direção NWN-SES.

As fraturas encontradas nas imediações do Rio Ivaí possuem alto grau de mergulho $\left(60^{\circ}\right.$ a $\left.90^{\circ}\right)$, chegando à verticalidade. Somente em um ponto de medição estrutural foi encontrado rejeito de $2 \mathrm{~cm}$ (P-23). As fraturas encontradas em campo podem ser inferidas como falhas em duas direções preferenciais N40W e N40E a N80E evidenciando duas famílias distintas de F1 e F2 respectivamente.

Devido ao caráter friável da Formação Caiuá, não foram encontrados indicadores cinemáticos suficientes que sustentem movimentações transcorrentes na área estudada. As técnicas e ferramentas aplicadas neste trabalho (análises de drenagem, estudo do fator de assimetria de bacias, análises de lineamentos estruturais em imagens de satélite e idas a campo) dão indícios de que as hipóteses levantadas são plausíveis. No entanto, somente com maior detalhamento dos estudos nesta área e com o uso de ferramentas geofísicas é que a hipótese inicial levantada neste trabalho pode ser confirmada.

Figura 9-Mapa morfotectônico interpretado da área 


\section{Agradecimentos}

ACAPES pela bolsa de mestrado durante os anos de 2010 e 2011. Aos técnicos e colaboradores de campo e de gabinete do GEMA(Grupo de Estudos Multidiciplinares do Ambiente: Fábio Alves, Everton Hafemann e Vanderlei Gregorczyk.

\section{Referências bibliográficas}

ALVES, F. C. Análise Geoambiental da Bacia Hidrográfica da Bacia do Rio Ivaí, PR. Trabalho de Conclusão do Curso de Geografia. Universidade Estadual de Maringá, PR- No prelo. 2012.

ANDRADE, A. R. Variabilidade da precipitação pluviométrica da bacia hidrográfica do rio Ivaí-PR. Dissertação de Mestrado em Geografia, Universidade Estadual de Maringá, (inédito). 2002.

BURBANK, D.W., ANDERSON, R.A. Tectonic Geomorphology, Blackwell Science, Malden, MA, USA. 2001.

BARROS, C. S. Dinâmica sedimentar e hidrológica na confluência do rio Ivaí com o rio Paraná, município de Icaraíma-PR. Maringá. Dissertação de Mestrado em Geografia, Departamento de Geografia, Universidade Estadual de Maringá (inédito), 53 p. 2006.

BIAZIN, P. C. Característica Sedimentar e Hidrológica do rio Ivaí em sua Foz com o rio Paraná, Icaraíma-PR. Dissertação de Mestrado em Geografia, Departamento de Geografia, Universidade Estadual de Maringá (inédito), 80 p. 2005.

BITTENCOURT, A. V. L. Transportes de sólidos na bacia hidrográfica do rio Ivaí. Boletim Paranaense de Geociências. Curitiba, n 35, 1982.

COUTO, E,C. Morfotectônica da Bacia do Rio AlonzoParaná. Dissertação (Mestrado. Departamento de Geografia. Universidade Estadual de Maringá). 2010.

DESTEFANI, E. V. Regime hidrológico do rio Ivaí. Dissertação (Mestrado em Geografia. Departamento de Geografia, Universidade Estadual de Maringá), 93 p. 2005.

FORTES, E.; STEVAUX, J. C.; VOLKMER, S. Neotectonics and channel evolution of the Lower Ivinhema River: A right-bank tributary of the upper Paraná River, Brazil. Geomorphology 70 325-338 p. 2005.

EMBRAPA. Levantamento de reconhecimento dos solos do Estado do Paraná - tomo I e II. Boletim técnico. Londrina: EMBRAPA/SNLCS/IAPAR, 1984. 791p.

FRANCO, A.L.A.; ETCHEBEHERE, M.L.C.; STEVAUX, J.C.; Hipótese sobre os condicionantes neotectônicos do barramento natural da foz do rio Ivaí (PR/MS) com base em levantamento ecobatimétrico. Revista da UnG-Geociências. V.7. N1. 2008. 75-86.

FUGITA, R. H. O perfil longitudinal do rio Ivaí e sua relação com a dinâmica de fluxos. Dissertação (Mestrado em Geografia, Departamento de Geografia, Universidade Estadual de Maringá), 01 p. 2009.
JABUR, I. C. Análise paleoambiental do Quaternário superior da bacia hidrográfica do Alto Paraná. 1992. 184 f. Tese (Doutorado Instituto de Geociências e Ciências Exatas, Universidade Estadual Paulista), Rio Claro, SP, 1992.

KURTEN, S. Variação longitudinal das características sedimentares e hidrológicas do rio Ivaí-PR em seu curso inferior. Dissertação (Mestrado em Geografia, Departamento de Geografia, Universidade Estadual de Maringá), 73 p. 2006.

MANIERI, D, D. Comportamento Morfoestrutural e Dinâmica das Formas de Relevo da Bacia Hidrográfica do Rio São Pedro - Faxinal- PR. Dissertação (Mestrado. Departamento de Geografia da Universidade Estadual de Maringá) 2010.

RAMOS, F. Vazões de estiagem em pequenas bacias hidrográficas do estado do Paraná. CEPHH. Curitiba, UFPR. 1973.

SANTOS, M. L. Estratigrafia e evolução dos sistemas siliciclásticos do rio Paraná em seu curso superior; ênfase à arquitetura dos depósitos e variação longitudinal das fácies. Tese (Doutorado do Departamento de Geologia da Universidade Federal do Rio Grande do Sul),1997.

SANTOS, M. L.; STEVAUX, J. C.; GASPARETTO, N. V. L.; SOUZA FILHO, E. E. Geologia e geomorfologia da planície do rio Ivaí-PR. In: Revista Brasileira de Geomorfologia, 2008.

SOARES, P.C.; FIORI, A.P. Lógica e sistemática na análise e interpretação de fotografias aéreas em geologia. Notícias Geomorfologia. Campinas, 16 (32): 71:104 p. 1976.

SOUZA JUNIOR, M. D. Efeitos tectônicos na formação da paisagem da bacia hidrográfica do rio Ivaí, curso inferior. Dissertação (Mestrado.Departamento de Geografia da Universidade Estadual de Maringá) 2012.

STANISTREET, I. G. ; MCCARTHY, T. S. The Okavango Fan and the classification of subaerial fan systems. Sedimentary Geology, 85: 115-133 p. 1993.

STEVAUX, J. C. O rio Paraná: geomorfogênese, sedimentação e evolução quaternária do seu curso superior (Região de Porto Rico, PR). Tese (Doutorado no Departamento de Geologia da Universidade de São Paulo), São Paulo-SP. 1993.

STEVAUX, J. C. Climatic events during the Late Pleistocene and Holocene in the UpperParana River: Correlation with NE Argentina and South-Central Brazil. Quaternary International, Oxford, GB, v. 72, p. 73-86, 2000.

STRAHLER, A. N. Global Geomorphology. New York, Jonh Wiley e Sons, 537p. 1952.

SUGUIO, K. Geologia Sedimentar. 1. ed. São Paulo: Editora Edgard Blücher, 2003.

TEIXEIRA, W.; TOLEDO, M. C. M. de; FAIRCHILD, T. R.; TAIOLI, F. (Orgs.) Decifrando a Terra. São Paulo: Oficina de Textos, 568 p. 2000. 